\title{
In reply: is dexmedetomidine really superior to propofol?
}

\author{
Kamath Sriganesh $^{1} \cdot$ Madhusudan Reddy $^{1}$ - G. S. Umamaheswara Rao ${ }^{1}$
}

Received: 25 April 2015 / Accepted: 27 April 2015 / Published online: 16 May 2015

(C) Japanese Society of Anesthesiologists 2015

\section{To the Editor:}

We thank Drs. Banik and Prabhakar for their comments [1] on our paper [2]. Based on the parameters we studied in 60 patients with subarachnoid hemorrhage (SAH), we found dexmedetomidine to be a better choice for sedation compared to propofol in spontaneously breathing patients for cerebral angiography. They opine that sample size calculation based on an earlier study might not hold well for our study. We differ with their observation. The study we used was closest to our design. The calculation of sample size depends on whether the outcome variable is quantitative or qualitative [3]. When qualitative parameters are used, sample size required is larger. It also depends on degree of difference the investigators wishes to accept between study and control groups. There are many formulas for different types of data and study designs. It is important that the parameter used for estimating the sample size should be one that measures treatment effects that we consider clinically relevant. In most studies, investigators use standard deviation from a pilot study or from published data [4]. Although previous studies have differences with the current study, such as dissimilar eligibility criteria and endpoints, data on control and treatment groups provide fair information for estimating sample size. It is better to perform sample size calculations for different outcome parameters and choose the largest sample size. We agree that sedation for diagnostic angiography needs to be evaluated further in patients of different grades of SAH.

\section{References}

1. Banik S, Prabhakar H. Is dexmedetomidine really superior to propofol? J Anesth. 2015. doi:10.1007/s00540-015-2005-0.

2. Sriganesh K, Reddy M, Jena S, Mittal M, Umamaheswara Rao GS. A comparative study of dexmedetomidine and propofol as sole sedative agents for patients with aneurysmal subarachnoid hemorrhage undergoing diagnostic cerebral angiography. J J Anesth. 2014. doi:10.1007/s00540-014-1952-1.

3. Charan J, Biswas T. How to calculate sample size for different study designs in medical research? Indian J Psychol Med. 2013;35:121-6.

4. Noordzij M, Tripepi G, Dekker FW, Zoccali C, Tanck MW, Jager KJ. Sample size calculations: basic principles and common pitfalls. Nephrol Dial Transpl. 2010;25:1388-93.

This comment refers to the article available at doi:10.1007/s00540-015-2005-0.

Kamath Sriganesh

drsri23@rediffmail.com

1 Department of Neuroanaesthesia, National Institute of Mental Health and Neurosciences (NIMHANS), Bangalore 560076, India 